\title{
A Note on Cash-in-Advance Constraints in Continuous Time
}

\section{Eric Kam}

Ryerson University

digital.library.ryerson.ca/object/16

Please Cite:

Kam, E. (2004). A note on cash-in-advance constraints in continuous time.

Economics Bulletin, 5(4), 1-8.

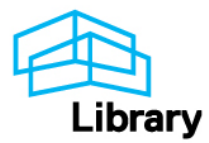




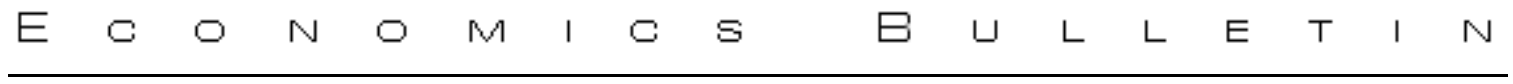

\title{
A note on cash-in-advance constraints in continuous time
}

\author{
Eric Kam \\ Ryerson University
}

\begin{abstract}
This paper demonstrates a robust proof of the continuous-time transformations of Stockman's cash-in-advance constraints. When the constraint applies to consumption and capital purchases, monetary growth lowers steady state consumption and capital. When the constraint applies only to consumption purchases, monetary growth is superneutral.
\end{abstract}

Financial assistance is gratefully acknowledged from the Dean of Arts, and SRC New Faculty Development Fund, Ryerson University. The author wishes to thank Paul Missios, Murat Yildiz and an anonymous referee for helpful comments. The usual caveat applies.

Citation: Kam, Eric, (2004) "A note on cash-in-advance constraints in continuous time." Economics Bulletin, Vol. 5, No. 4 pp. $1-8$

Submitted: November 1, 2003. Accepted: February 11, 2004.

URL: http://www.economicsbulletin.com/2004/volume5/EB-03E00008A.pdf 


\section{Introduction}

Stockman (1981) demonstrates the inflationary implications of two independent cashin-advance constraints. If the cash-in-advance constraint applies to the purchase of capital and consumption goods, inflation decreases steady state capital and inverts the real sector implications of the Mundell-Tobin effect. However, if the constraint applies strictly to the purchase of consumption goods, inflation does not affect the capital stock. Stockman first derived the cash-in-advance constraint models in discrete-time. This paper transforms the two cash-in-advance constraint models into continuous-time to demonstrate the effects of monetary growth targeting on steady state real sector variables. Monetary growth reduces steady state consumption and capital or generates monetary superneutrality depending on underlying modeling assumptions and whether the constraint applies to consumption and capital purchases or a consumption good alone.

Modeling a cash-in-advance constraint in continuous time is relatively new. However, many papers have used this technique in more complicated monetary models without first demonstrating whether the continuous-time transformation is consistent with the discretetime model. ${ }^{1}$ If this transformation from discrete to continuous-time is not consistent, it is hard to establish whether the new cash-in-advance constraint provides the microeconomic underpinnings to study the underlying causality behind changes in steady state real sector variables (Smithin 2004). This paper supports many recent publications that integrate this transformation by providing a mathematical proof of its robustness.

Section 2 demonstrates the representative agent problem and the steady state effect of monetary growth if the constraint applies to the purchase of both consumption and capital

\footnotetext{
${ }^{1}$ See Calvo (1987), Wang and Yip (1992), Carlstrom and Fuerst (1995, 1998), Svensson (1985) and Mansoorian and Mohsin (2004).
} 
goods. Section 3 analyzes a special case of the constraint that applies strictly to purchases of a consumption good. The final section offers concluding comments.

\section{A Cash-in-Advance Constraint on Consumption and Capital}

Stockman models a cash-in-advance constraint that applies to the purchase of capital and consumption goods. In continuous-time, this constraint becomes ${ }^{2}$

$$
m_{t} \geq c_{t}+\dot{k}_{t}
$$

where $c$ is consumption, $m$ is a stock of real balance holdings and $k$ is capital. ${ }^{3}$

Consider a monetary growth model where real balances do not yield utility but appear in the definition of real wealth, and the asset accumulation identity. Representative agents are infinitely-lived with perfect foresight and complete access to capital. They maximize

$$
u_{0}=\int_{0}^{\infty} u\left(c_{t}\right) e^{-\theta t} d t
$$

subject to three flow budget constraints ${ }^{4}$

$$
\begin{gathered}
\dot{a}_{t}=f\left(k_{t}\right)+x_{t}-c_{t}-\pi_{t} m_{t} \\
m_{t}=c_{t}+\dot{k}_{t} \\
a_{t}=m_{t}+k_{t}
\end{gathered}
$$

and two stock budget constraints

$$
\begin{aligned}
& \lim _{t \rightarrow \infty} a_{t} e^{-\int_{0}^{t} r_{v} d v} \geq 0 \\
& \lim _{t \rightarrow \infty} k_{t} e^{-\int_{0}^{t} r_{v} d v} \geq 0
\end{aligned}
$$

\footnotetext{
${ }^{2}$ Since money does not yield utility, the nominal interest rate is positive and (1) holds with strict equality.

${ }^{3}$ Capital depreciation is assumed to be zero throughout with no loss of generality.

${ }^{4}$ Where $u_{c}>0$ and $u_{c c}<0$.
} 
where $f$ is a constant returns to scale production function, $x$ is the value of public sector transfers to hold real balances constant following inflation, $a$ is real wealth, $\pi$ is the rate of inflation, $\theta$ is an exogenous rate of time preference and $r$ is the real interest rate. Substitute (5) into (4) and (3) to get

$$
\begin{gathered}
\dot{k}_{t}=a_{t}-k_{t}-c_{t} \\
\dot{a}_{t}=f\left(k_{t}\right)+x_{t}-c_{t}-\pi\left(a_{t}-k_{t}\right)
\end{gathered}
$$

Maximizing (2) subject to (8), (9), (6) and (7) yields first order optimality conditions

$$
\begin{gathered}
u_{c}(c)-(\lambda+\gamma)=0 \\
\gamma \theta-\lambda\left(f^{\prime}(k)+\pi\right)+\gamma=\dot{\gamma} \\
\lambda \theta+\lambda \pi-\gamma=\dot{\lambda} \\
\lim _{t \rightarrow \infty} a_{t} \lambda_{t} e^{-\theta t}=0 \\
\lim _{t \rightarrow \infty} k_{t} \gamma_{t} e^{-\theta t}=0
\end{gathered}
$$

where (13) and (14) are transversality conditions and $\lambda$ and $\gamma$ are two co-state variables. In the steady state, from (11) with $\dot{\gamma}=0$

$$
\gamma \theta-\lambda\left(f^{\prime}\left(k^{*}\right)+\pi\right)+\gamma=0
$$

from (12) with $\dot{\lambda}=0$

$$
\lambda \theta+\lambda \pi-\gamma=0
$$

from (8) and (5) with $\dot{k}=0$

$$
c^{*}=m^{*}
$$

The resource constraint is

$$
\dot{k}=f(k)-c
$$


From (18) with $\dot{k}=0$ implies

$$
c^{*}=f\left(k^{*}\right)
$$

From (3) and (19) with $\dot{a}=0$, the result is $x^{*}=m^{*} \pi^{*}=\mu m^{*}$, which implies

$$
\pi^{*}=\mu
$$

where $\mu$ is the monetary growth rate.

Linearize (10), (15), (16), (17) and (19) around steady state consumption, capital and real balances $\left(c^{*}, m^{*}, k^{*}\right)$ using $(20)$, yields

$$
\left[\begin{array}{ccccc}
u_{c c} & 0 & 0 & -1 & -1 \\
0 & -\lambda f^{\prime \prime} & 0 & (1+\theta) & -\left(f^{\prime}+\mu\right) \\
0 & 0 & 0 & -1 & (\theta+\mu) \\
-1 & f^{\prime} & 0 & 0 & 0 \\
-1 & 0 & 1 & 0 & 0
\end{array}\right]\left[\begin{array}{c}
d c^{*} \\
d k^{*} \\
d m^{*} \\
d \gamma \\
d \lambda
\end{array}\right]=\left[\begin{array}{c}
0 \\
\lambda \\
-\lambda \\
0 \\
0
\end{array}\right] d \mu
$$

The determinant of the coefficient matrix in (21) is:

$$
|\Delta|=\left(\lambda f^{\prime \prime}\right)(-1-(\theta+\mu))>0
$$

The effect of monetary growth on steady state capital and consumption is given by

$$
\frac{d k^{*}}{d \mu}=\frac{d c^{*}}{d \mu}=\frac{-\lambda\left(f^{\prime}\right)^{2}}{|\Delta|}<0
$$

Substitution effects raise the opportunity cost of holding real balances, which reduces the initial levels of real wealth, real balances and the rate of time preference but increases savings. Whether the added savings raises or lowers steady state consumption and capital depends on the relative magnitudes of two contradictory wealth effects. First, the cash-inadvance constraint acts as an investment tax that directs the added savings away from the production and demand for steady state real sector variables. However, the decline in real wealth generates wealth effects that convert the additional savings from real balances into 
steady state capital and consumption through a Mundell-Tobin type process. As the cashin-advance constraint effect dominates the wealth effect, monetary growth reduces steady state capital and consumption to invert the real implications of the Mundell-Tobin effect.

\section{A Cash-in-Advance Constraint on Consumption}

The alternative cash-in-advance constraint applies strictly to consumption purchases.

A continuous-time transformation of this constraint yields

$$
c_{t} \leq m_{t}
$$

Substitute (5) and (24) into (3) to obtain a single flow budget constraint ${ }^{5}$

$$
\dot{a}_{t}=f\left(a_{t}-c_{t}\right)+x_{t}-c_{t}\left(1+\pi_{t}\right)
$$

Maximize (2) subject to (25) and (6) to get the first order optimality conditions

$$
\begin{gathered}
u_{c}(c)-\phi\left(f^{\prime}(a-c)+(1+\pi)\right)=0 \\
\phi \theta-\phi f^{\prime}(a-c)=\dot{\phi} \\
\lim _{t \rightarrow \infty} a_{t} \phi_{t} e^{-\theta t}=0
\end{gathered}
$$

where (28) is the transversality condition and $\phi$ is the co-state variable.

In the steady state, from (27) with $\dot{\phi}=0$ yields

$$
\theta=f^{\prime}(k)
$$

Linearize (26), (29) and (19) around $\left(c^{*}, k^{*}\right)$ using (20), yields

$$
\left[\begin{array}{ccc}
u_{c c} & -f^{\prime \prime} \phi & -\alpha \\
0 & f^{\prime \prime} & 0 \\
-1 & f^{\prime} & 0
\end{array}\right]\left[\begin{array}{l}
d c^{*} \\
d k^{*} \\
d \phi^{*}
\end{array}\right]=\left[\begin{array}{l}
\phi \\
0 \\
0
\end{array}\right] d \mu
$$

where $\alpha=1+\mu+f^{\prime}>0$. The determinant of the coefficient matrix in (30) is:

\footnotetext{
${ }^{5}$ Money does not yield utility so that the nominal interest rate is positive and (24) holds with strict equality.
} 


$$
|A|=-f^{\prime \prime} \alpha>0
$$

The effect of monetary growth on steady state capital and consumption is given by

$$
\frac{d k^{*}}{d \mu}=\frac{d c^{*}}{d \mu}=\frac{0}{|A|}
$$

Monetary growth raises the real costs of consumption and the opportunity cost of real balance holdings. The demand for money is residually determined so that the substitution effect lowers the demand for consumption goods by raising the initial level of real wealth and savings. However, this generates wealth effects that raise the demand for steady state consumption goods and reduce savings. Therefore, imposing a cash-in-advance constraint solely on purchases of consumption goods produces contradictory substitution and wealth effects. As the two effects are of equal magnitude, monetary growth does not produce any change in the demand for steady state real sector variables and is superneutral.

\section{Conclusions}

This paper transforms Stockman’s cash-in-advance constraint models into continuous time to demonstrate the effect of monetary growth on consumption and capital. When the cash-in-advance constraint is applied to both consumption and capital good expenditures, monetary growth generates an investment tax that reduces the steady state production and demand of both goods to reverse the real sector implications of the Mundell-Tobin effect. However, when the cash-in-advance constraint applies only to purchases of consumption goods, monetary growth does not affect the real sector. Without the investment tax effect, exogenous time preference holds the marginal product of capital and the real interest rate constant. Steady state capital and consumption are not affected by monetary changes and monetary policy is therefore superneutral. This paper provides necessary microeconomic 
underpinnings for continuous-time cash-in-advance constraints by offering mathematical verification of their robustness.

\section{References}

Calvo, G. (1987) “Balance of payments crisis in a cash-in-advance economy,” Journal of Money, Credit and Banking 19, 19-32

Carlstrom, C., and T. Fuerst (1995) "Interest rate rules vs. money growth rules: a welfare comparison in a cash-in-advance economy,” Journal of Monetary Economics 36, 24767

----- (1998) “A note on the role of countercyclical monetary policy,” Journal of Political Economy 106, 860-66

Mansoorian, A., and M. Mohsin (2004) "Monetary policy in a cash-in-advance economy: employment, capital accumulation and the term structure of interest rates” Canadian Journal of Economics, forthcoming

Smithin, J. (2004) Controversies in Monetary Economics, Cheltenham: Edward Elgar.

Stockman, A. (1981) “Anticipated inflation and the capital stock in a cash-in-advance economy,” Journal of Monetary Economics, 8, 387-93

Svensson, L. (1995) “Money and asset prices in a cash-in-advance economy,” Journal of Political Economy 93, 919-44

Wang, P., and C. Yip (1992) “Alternative approaches to money and growth,” Journal of Money, Credit, and Banking 24, 553-62 